\title{
Isqueiro Pneumático: uma ferramenta versátil ao ensino interdisciplinar
}

Pneumatic Lighter: a versatile tool to the interdisciplinary teaching

\author{
Thiago de Cacio Luchese ${ }^{* 10}$, Roger Matias Vogt ${ }^{1}$, Rosália Andrighetto ${ }^{1}$ \\ ${ }^{1}$ Universidade Federal da Fronteira Sul, Cerro Largo, RS, Brasil
}

\begin{abstract}
Recebido em 28 de Setembro, 2018. Revisado em 29 de Novembro, 2018. Aceito em 31 de Dezembro, 2018.
O isqueiro pneumático é um equipamento que permite produzir fogo por meio de rápida compressão do ar e, quando construído com tubo de acrílico transparente, é possível observar a queima de uma pequena amostra de algodão colocada em seu interior. Por ser um instrumento pouco conhecido e cujo funcionamento chama a atenção vislumbramos seu uso em sala de aula como ferramenta auxiliar na construção significativa de conceitos de Termodinâmica, tanto na Física quanto na Química do processo, podendo ser usado como articulador de interdisciplinaridade. As muitas conversões de energia observadas no processo podem alavancar o interesse em conceitos que vão para além daqueles restritos à Termodinâmica. Em especial, relatamos como podem ser feitas estimativas da energia liberada no processo de queima do algodão utilizando para isso um software livre para processamento de vídeos quadro a quadro, o Tracker. Esperamos que este trabalho venha a divulgar o isqueiro pneumático como ferramenta de ensino para a Física e Química, estimular o uso de experiências simples em sala de aula visando o desenvolvimento significativo do conhecimento e evidenciar que a aquisição e o processamento de dados pode mostrar-se atividade potencialmente lúdica de investigação em física clássica já no nível médio de ensino.
\end{abstract}

Palavras-chave: máquinas térmicas, pistão de fogo, termodinâmica, compressão adiabática, reações exotérmicas.

\begin{abstract}
The pneumatic lighter is a device that allows to produce fire by means of rapid air compression and, when constructed with transparent acrylic tube, it is possible to observe the burning of a small sample of cotton placed in its interior. Because it is a little known instrument and whose operation calls attention we see its use in the classroom as an auxiliary tool in the significant construction of concepts of thermodynamics, both in physics and in the chemistry of the process, so that it can be used as an articulator of interdisciplinary. The many energy conversions observed in the process can also leverage interest in concepts that go beyond those restricted to thermodynamics. In particular, we report how can be made estimates of the energy released in the cotton burning process using a free software for video processing frame by frame, Tracker. We hope that this work will divulge the pneumatic lighter as a teaching tool for Physics and Chemistry, to stimulate the use of simple experiments in the classroom aiming at the significant development of knowledge and to show that the acquisition and processing of data can be shown potentially playful activity of research in classical physics already at the average level of education.
\end{abstract}

Keywords: thermal machines, fire piston, thermodynamics, adiabatic compression, exothermic reactions.

\section{Introdução}

O uso de uma bomba de ar manual para inflar um pneu, uma bola, um colchão de ar etc., possibilita constatar que o ar sofre aumento de temperatura quando comprimido. Tal conclusão irrefutável advém da percepção tátil de que a extremidade do corpo da bomba que expele o ar comprimido fica levemente mais quente que o restante de sua estrutura após vários ciclos de compressão.

Pode ser que esse experimento, por ser tão simples, não venha a provocar nossa curiosidade para explorar o fenômeno de aquecimento por compressão. No entanto, será que repensaríamos nele se fosse possível ver fogo

*Endereço de correspondência: thiago.luchese@uffs.edu.br sendo gerado a partir do aquecimento do ar por rápida compressão? Ou, ainda, se fosse possível mostrar que tal aquecimento é responsável por fazer o motor de um automóvel funcionar?

Um isqueiro pneumático, também conhecido como pistão de fogo, é um equipamento utilizado para gerar fogo utilizando o princípio de aquecimento pela rápida compressão do ar. Quando tal equipamento é construído com acrílico transparente é possível visualizar a queima de uma pequena amostra de algodão inserida no interior do equipamento, tornando a experiência motivadora e atraente ao estudo da Termodinâmica como um todo.

Uma pesquisa no Google e no Google Acadêmico dos termos "isqueiro pneumático" ou "pistão de fogo" permite evidenciar a pouca disponibilidade de textos em 
português que abordem a história do equipamento 1,2 ou que expliquem como estimar a temperatura e a pressão atingidas no momento da queima [3], apesar de tais estimativas poderem ser feitas facilmente, pelo menos em uma primeira abordagem quantitativa do fenômeno, com conhecimentos presentes já no nível médio de ensino.

Espera-se que este trabalho venha a ser útil no sentido de evidenciar que as estimativas a respeito da temperatura e pressão no instante da queima não são, de fato, difíceis de serem realizadas e, adicionalmente, que quantificar a energia liberada no momento da queima e a força mínima necessária para ativar o fogo no isqueiro pneumático é uma tarefa factível sem muito esforço adicional.

Indo um pouco para além dessas abordagens quantitativas, pretende-se que ao final do artigo o equipamento tenha se revelado em suas muitas potencialidades como ferramenta de ensino propulsora de discussões interdisciplinares diretas entre Física e Química e indiretas com História (as máquinas térmicas tiveram papel relevante no desenrolar da Revolução Industrial), Sociologia (a Revolução Industrial provocou rearranjo social), Geografia (mudanças climáticas e de relevo ocorreram devido à possibilidade de exploração de matérias primas em grande escala), para citar algumas.

A parte quantitativa do estudo do fenômeno foi viabilizada por meio da construção de um conjunto de três isqueiros pneumáticos de acrílico transparente. $\mathrm{O}$ acionamento simultâneo dos isqueiros através do abandono de uma massa conhecida sobre a mesa de acoplamento do conjunto foi filmado e, com auxílio do software livre Tracker [4], a trajetória de queda da mesa de acionamento foi determinada. Essa trajetória permitiu modelar a força resultante sobre a mesa no processo de queda e estimar a energia liberada na queima do algodão, adquirindo com isso subsídios experimentais para explicar de maneira simples a base de funcionamento dos atuais motores de explosão interna. Tal procedimento de aquisição e processamento de dados pode ser encarado potencialmente como uma "brincadeira" de filmar e analisar quadro a quadro um vídeo, tornando a abordagem de novos conceitos e a quantificação destes mais atraente e, possivelmente, auxiliando o processo de aprendizado significativo.

Embora o processamento e a interpretação dos dados conforme a descrição a ser dada a seguir não seja viável no nível médio de escolarização, entende-se que nesse nível os estudantes poderiam ter sua curiosiosidade aguçada para as ciências naturais ao vivenciar a possibilidade de investigação quantitativa de fenômenos com ferramentas acessíveis à ampla maioria das pessoas.

A sequência de apresentação do trabalho é a seguinte: na Seção2 descrevemos as características do equipamento utilizado neste trabalho com a finalidade de produzir dados quantitativos a respeito do funcionamento do isqueiro pneumático enquanto que, na Seção 3 . encontra-se a descrição da metodologia de aquisição desses dados. A Seção 4 modela teoricamente o experimento e apresenta as esti- mativas de temperatura, pressão e a energia liberada no instante da queima e, ainda, a equação de movimento com dois parâmetros livres, um de atrito e outro de possível escape de partículas, para melhor ajustar as trajetórias observada e teórica. Por fim, na Seção 5, são tecidas observações gerais sobre a execução do experimento, interpretação de resultados, aplicações ao ensino de Física e Química e possíveis novas investigações associadas ao equipamento experimental.

\section{Equipamento experimental}

Para construir um isqueiro pneumático a ser utilizado em sala de aula bastam uma base de madeira, um pequeno cilindro de aço a ser fixado na base, um tubo de acrílico e o pistão de aço com um cabo em sua extremidade. À esquerda da Figura 1 estes elementos são apresentados, a base (1) tendo as dimensões (comprimento x largura $\mathrm{x}$ altura $)=(10,0 \times 10,0 \times 2,5) \mathrm{cm}$, o cilindro pequeno de aço (2) (diâmetro $\mathrm{x}$ altura) $=(8,7 \times 22,7) \mathrm{mm}$, o cilindro grande de aço (3) (diâmetro $\mathrm{x}$ altura) $=(8,8$ $\mathrm{x}$ 170) $\mathrm{mm}$ e o tubo de acrílico (4) (diâmetro interno $\mathrm{x}$ diâmetro externo $\mathrm{x}$ altura $)=(9,0 \times 15,0 \times 198) \mathrm{mm}$. Ao centro desta figura apresenta-se o equipamento montado e pronto para uso e, finalmente, à direita o equipamento em funcionamento no instante da queima da amostra de algodão em seu interior.

Como detalhe, deve-se notar a pequena diferença entre o diâmetro do cilindro de aço grande e o diâmetro interno do tubo de acrílico, possibilitando escorregamento livre do primeiro no interior do segundo, bem como a presença de borrachas de vedação em ambos os cilindros de aço que tornam a conexão entre estes e o tubo de acrílico devidamente justa para impedir o vazamento de ar do interior do isqueiro pneumático durante o processo de compressão e queima do algodão. Daqui pra frente
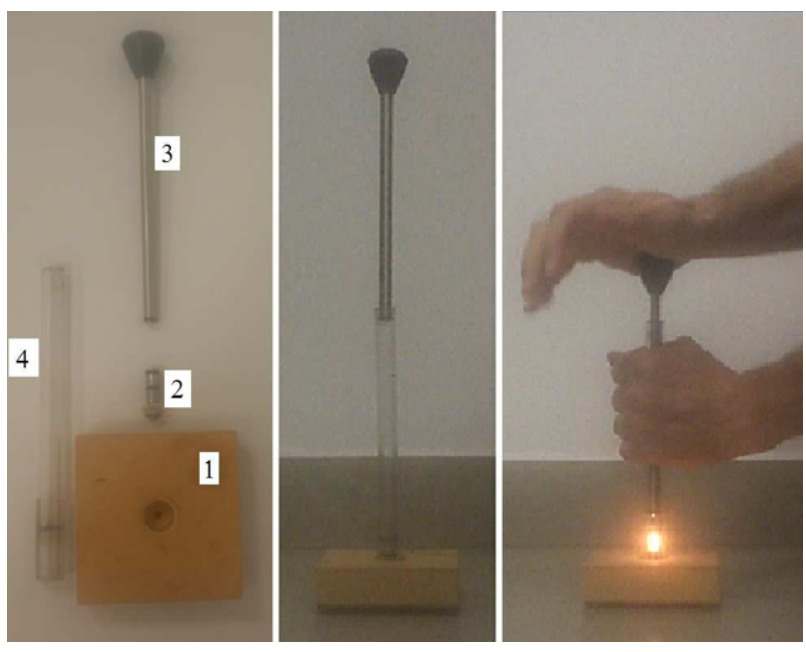

Figura 1: Um isqueiro pneumático para uso em sala de aula desmontado (à esquerda), montado (ao centro) e no instante da queima da amostra de algodão em seu interior (à direita). 
chamaremos o cilindro grande de aço de pistão e o tubo de acrílico de camisa do pistão.

Uma vez que desejamos realizar um experimento controlável e reprodutível, com a finalidade de quantificar grandezas como energia liberada na queima e a força necessária para ativar a queima do algodão, o equipamento utilizado neste trabalho precisou ser um pouco mais elaborado. Ao invés de apenas um isqueiro pneumático foram construídos três deles, sendo todos os três fixados em uma mesma base (esta denominada de base fixa daqui pra frente) e acionados simultaneamente através do acoplamento dos pistões em uma segunda base (esta denominada de base com os pistões daqui pra frente). Este conjunto pode ser visualizado na Figura 2 A base com os pistões, ao ser acionada pelo abandono de uma massa conhecida sobre ela, permite controlar e quantificar a força aplicada sobre o conjunto dos três pistões. A trajetória desta base em função do tempo quando o equipamento é acionado servirá de dado experimental para validação do modelo teórico do fenômeno, modelo este a ser desenvolvido na Seção 4

As dimensões do conjunto apresentado na Figura 2 são: madeira inferior da base fixa (1) (comprimento x largura $\mathrm{x}$ altura $)=(20,0 \times 20,0 \times 3,8) \mathrm{cm}$, madeira superior da base fixa (2) (comprimento $\mathrm{x}$ largura $\mathrm{x}$ altura) $=$ $(20,0 \times 20,0 \times 2,0) \mathrm{cm}$, parafusos de acoplamento das madeiras inferior e superior da base fixa (3) (diâmetro x comprimento $)=(9,5 \times 300) \mathrm{mm}$, madeira da base com os pistões (4) (comprimento $\mathrm{x}$ largura $\mathrm{x}$ altura $)=(20,0$ x 20,0 x 2,0) cm, cilindro pequeno de aço (5) (diâmetro x comprimento $)=(11,0 \times 20,0) \mathrm{mm}$, pistões $(6)$ (diâmetro $\mathrm{x}$ comprimento $)=(11,0 \times 301) \mathrm{mm}$, camisas dos pistões

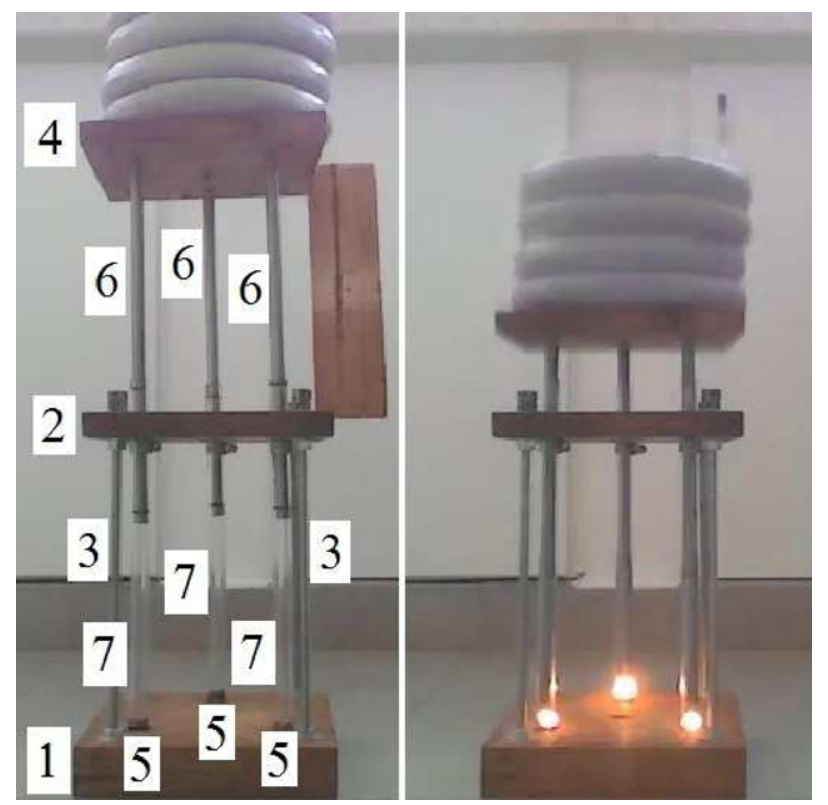

Figura 2: $\mathrm{O}$ conjunto de três isqueiros pneumáticos utilizado neste trabalho. À esquerda nota-se o cojunto montado pronto para ser observado funcionando, à direita o instante da queima nos três isqueiros pneumáticos.
(7) (diâmetro interno x diâmetro externo x comprimento) $=(11,3 \times 15,4 \times 298) \mathrm{mm}$.

\section{Aquisição de dados}

Para posterior avaliação quantitativa de temperatura e pressão no instante da queima faz-se necessário relatar que no dia em que foram feitos os vídeos para levantamento dos dados experimentais a temperatura ambiente era de $27^{\circ} \mathrm{C}$ e a pressão atmosférica 0,96 atm.

Foram produzidas vinte e cinco gravações do aparato experimental em funcionamento, sendo cinco vídeos repetidos para cada uma das cinco situações distintas sob investigação. As cinco situações distintas investigadas foram as seguintes:

1) Queda sem queima e carga de $10 \mathrm{~kg}$;

2) Queda sem queima e carga de $15 \mathrm{~kg}$;

3) Queda sem queima e carga de $20 \mathrm{~kg}$;

4) Queda com queima e carga de $15 \mathrm{~kg}$;

5) Queda com queima e carga de $20 \mathrm{~kg}$.

As situações 1, 2 e 3 possibilitaram investigar o processo de dissipação de energia mecânica no equipamento. Já os pares de situações $(2,4)$ e $(3,5)$ permitiram quantificar a energia gerada no processo de queima. Por fim, a constatação de que não há queima com carga de 10 kg e há com carga de $15 \mathrm{~kg}$, situações 1 e 4, permite avaliar a força mínima sobre a base com os pistões capaz de gerar a ignição do algodão no interior dos isqueiros pneumáticos.

Cabe observar que as situações (1-3) foram produzidas sem algodão dentro do isqueiro pneumático, de modo que a não existência de uma situação com queima e carga de $10 \mathrm{~kg}$ decorre do fato de esta carga não ter gerado as condições de temperatura e pressão necessárias para a combustão do algodão no interior do equipamento.

Cada acionamento do aparato para produção de vídeo foi feito repetindo-se a seguinte sequência de ações:

i) A base com pistões foi separada da base fixa;

ii) Cada uma das seis borrachas dos pistões foi lubrificada com vaselina;

iii) Cada um dos tubos de acrílico foi desconectado da base fixa;

iv) Uma amostra de algodão foi posicionada sobre cada um dos pequenos cilindros de aço da base fixa;

v) Os tubos de acrílico foram novamente posicionados na base fixa, tomando-se o cuidado pra deixar a amostra de algodão livre ao ar a ser aprisionado e comprimido nas camisas dos pistões;

vi) A base com os pistões foi então posicionada novamente sobre a base fixa, vedando cada um dos tubos de acrílico;

vii) Um suporte de madeira foi posicionado entre a base com os pistões e a base fixa, com a finalidade de manter a base com pistões fixa enquanto uma certa massa era posicionada acima dela; 
viii) A massa responsável pela força de ativação do equipamento foi então adicionada sobre a base com pistões;

ix) Dá-se início à gravação do vídeo;

$\mathrm{x})$ Um piparote é dado no suporte de madeira acrescentado no passo (vii), permitindo que a massa adicionada no passo (viii) caia "livremente" e gere (ou não) as condições de temperatura e pressão que dão ignição à queima do algodão em cada isqueiro pneumático;

xi) a gravação do vídeo é encerrada quando cessa a oscilação da base com os pistões.

Os vídeos foram produzidos com a câmera integrada de um computador portátil, sendo a distância entre a câmera e a frente (em relação à câmera) da base fixa do equipamento de $82 \mathrm{~cm}$.

A análise e levantamento de dados de cada um dos vídeos foi efetuada utilizando-se o software livre Tracker [4]. No ambiente do software faz-se necessário o estabelecimento de um sistema coordenado e de um bastão de escala sobre um quadro do vídeo sob análise. Estes dois itens, quando especificados, possibilitam a determinação da trajetória da base com os pistões em função do tempo.

Uma vez que cinco vídeos distintos foram produzidos para cada situação experimental, a trajetória a ser analisada para interpretação de dados consistiu da média aritmética simples das cinco trajetórias, assumindo-se o desvio padrão amostral da média como o erro da posição da base com os pistões para cada tempo amostrado.

Para determinação de cada uma das vinte e cinco trajetórias disponíveis foi adotada a seguinte sequência de passos:

i) O sistema coordenado do Tracker foi posicionado com origem coincidente com a parte superior do canto superior esquerdo da madeira superior da base fixa, estando o eixo x orientado para direita e paralelo à parte superior da madeira superior da base fixa e o eixo y orientado para cima e perpendicular ao x;

ii) O bastão de calibração, que estabelece a escala de distâncias no vídeo, foi posicionado paralelamente ao eixo x, sobre a linha inferior da madeira superior da base fixa, sendo os extremos do bastão coincidentes com as bordas desta madeira superior da base fixa, de modo a determinar a escala de $20,0 \mathrm{~cm}$ para este bastão;

iii) O início de contagem do tempo, determinado pelo primeiro quadro a ser analisado no Tracker em cada vídeo, se deu com o primeiro quadro onde era observado o suporte da base com os pistões (passo vii da produção dos vídeos) estar fora da base fixa devido ao piparote nele dado (passo x da produção dos vídeos) para iniciar o processo de queda da base com os pistões;

iv) O término de contagem do tempo nos vídeos foi determinado pelo terceiro quadro de cada vídeo onde não era mais observada modificação de posição da base com os pistões;

v) O ponto de referência seguido pelo Tracker quadro a quadro, por meio de marcação automática, foi o canto inferior esquerdo da madeira da base com os pistões.
Cabe observar aqui que houveram alguns quadros onde a marcação da posição do ponto de referência para trajetória teve de ser realizada manualmente, uma vez que o Tracker não conseguiu identificá-lo automaticamente; o número de ocorrências desta situação foi inferior a um quadro por trajetória analisada.

As trajetórias construídas com a metodologia descrita acima para as cargas de $10 \mathrm{~kg}, 15 \mathrm{~kg}$ e $20 \mathrm{~kg}$ são apresentadas, com seus respectivos erros, nas Figuras 3,4 e 5. Uma vez que a carga de $10 \mathrm{~kg}$ não foi capaz de dar ignição ao processo de queima do algodão no interior do isqueiro pneumático, queima esta observada para carga superior ou igual a $15 \mathrm{~kg}$, somos capazes de estimar a força mínima necessária para gerar a queima do algodão. Também, uma vez que nas trajetórias dos casos de carga $15 \mathrm{~kg}$ ou $20 \mathrm{~kg}$ nota-se uma maior subida da base com pistões para aquelas trajetórias com queima do que naquelas sem queima, somos capazes de usar esta diferença entre picos de trajetórias para evidenciar e possibilitar fazer estimativa da energia mínima liberada no processo de queima do algodão.

\section{Estimando grandezas}

Estimativas aproximadas da temperatura e pressão atingidas no interior do isqueiro pneumático no momento da queima da amostra de algodão podem ser realizadas utilizando-se as equações de estado de um gás ideal de moléculas diatômicas sob compressão adiabática $[5,6]$. A justificativa de adiabaticidade do processo durante a compressão está no fato de que esta se dá em um tempo muito menor do que aquele necessário para que hajam

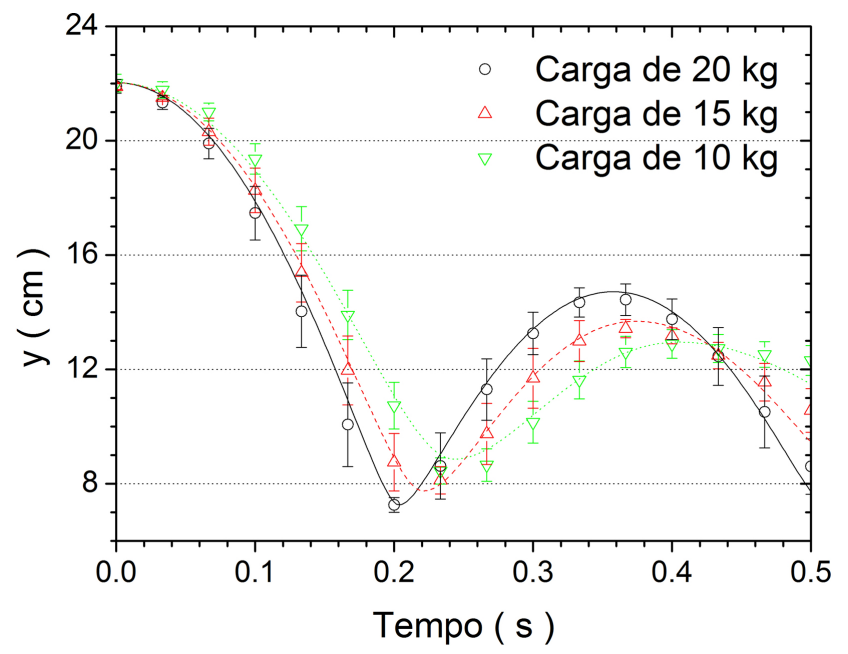

Figura 3: Trajetória média da base com pistões sem queima do algodão para as cargas de $10 \mathrm{~kg}$ (triângulos verdes e invertidos), $15 \mathrm{~kg}$ (triângulos vermelhos e em pé) e $20 \mathrm{~kg}$ (círculos pretos). As linhas de fundo foram geradas numericamente a partir da equação de movimento (10) sendo a linha verde pontilhada obtida com os parâmetros $f_{1}=11 \mathrm{~N}$ e $f_{2}=0,59$, a linha vermelha tracejada com os parâmetros $f_{1}=9,6 \mathrm{~N}$ e $f_{2}=0,58$ e a linha sólida preta com os parâmetros $f_{1}=0 \mathrm{~N}$ e $f_{2}=0,56$. 
trocas de calor entre o interior do isqueiro e o meio que o circunda. Por sua vez, o gás comprimido pode ser considerado diatômico devido ao fato de a atmosfera consistir em uma mistura gasosa com mais de $95 \%$ de moléculas deste tipo: nitrogênio $\left(\mathrm{N}_{2}\right)$ e oxigênio $\left(\mathrm{O}_{2}\right)$.

$\mathrm{Na}$ compressão adiabática de um gás ideal diatômico, a pressão $(p)$ e o volume $(V)$ estão relacionados entre si por meio da equação

$$
p V^{\gamma}=\text { constante }=p_{0} V_{0}^{\gamma}
$$

sendo $p_{0}$ a pressão atmosférica, $V_{0}$ o volume do gás no início do processo de compressão e $\gamma=7 / 5$. Uma vez que $V=\pi r^{2} h$, sendo $r$ o raio interno da camisa do pistão e $h$ a altura disponível para o gás aprisionado na camisa do pistão, a equação (1) pode ser rearranjada para fornecer a pressão $p_{q}$ no instante da queima

$$
p_{q}=\left(\frac{h_{0}}{h_{q}}\right)^{\gamma} p_{0}
$$

sendo $h_{0}$ a altura disponível ao ar no instante em que se dá o início da descida da base com pistões e $h_{q}$ a altura disponível ao ar no instante da queima do algodão.

Tanto para o caso de queima com carga $15 \mathrm{~kg}$ quanto para o caso de carga $20 \mathrm{~kg}$, uma verificação direta do quadro do vídeo em que esta queima é observada permite estimar $h_{q}=1,1 \mathrm{~cm}$. O quadro inicial das trajetórias levou à estimativa de $h_{0}=15,3 \mathrm{~cm}$. Desse modo, lembrando que a pressão atmosférica na data da aquisição dos vídeos era $p_{0}=0,96 \mathrm{~atm}$, estes dados são levados na equação 2 e estimamos a pressão no instante da queima como tendo o valor aproximado de $p_{q}=38,3 \mathrm{~atm}$.

Se utilizarmos a equação de estado para gases ideais $p V=n R T$, em que $p$ representa a pressão, $V$ o volume, $n$ o número de moles da amostra de gás ideal, $R$ a constante universal dos gases ideais e $T$ a temperatura, para escrever a pressão como função do volume $(p=n R T / V)$ e, em seguida, substituirmos esta expressão da pressão na equação (1), podemos obter a relação entre volume e temperatura no processo de compressão adiabática. Tal relação é dada por

$$
T V^{\gamma-1}=\text { constante }=T_{0} V_{0}^{\gamma-1}
$$

Mais uma vez, usamos $V=\pi r^{2} h$ para reescrever a equação (3) de modo a poder estimar a temperatura $T_{q}$ no instante da queima

$$
T_{q}=\left(\frac{h_{0}}{h_{q}}\right)^{\gamma-1} T_{0}
$$

sendo $h_{0}$ a altura disponível ao ar no instante em que inicia-se a descida da base com pistões e $h_{q}$ a altura disponível ao ar no instante da queima do algodão. Utilizando os valores de $h_{0}$ e $h_{q}$ idênticos àqueles da determinação da pressão no interior do isqueiro pneumático no instante da queima, e lembrando que a temperatura ambiente na data da coleta dos vídeos era de $T_{0}=27^{\circ} \mathrm{C}=300 \mathrm{~K}$, estimamos a temperatura no interior do isqueiro pneumático no instante da queima como tendo o valor $T_{q}=860$ $\mathrm{K}=587^{\circ} \mathrm{C}$.

Por sua vez, a energia liberada através da combustão acaba por manifestar-se, efetivamente, como energia potencial gravitacional e pode ser estimada pela diferença de altura entre as trajetórias com e sem a queima de algodão, nos casos de carga $15 \mathrm{~kg}$ (Figura 4) e $20 \mathrm{~kg}$ (Figura 5 onde observa-se a ocorrência de tal queima.

A energia potencial gravitacional $U_{g}$ associada a uma diferença de altura $\Delta h$ é estimada a partir da expressão

$$
U_{g}=m g \Delta h
$$

onde $m$ representa a massa de queda livre (a massa sobre a base com os pistões acrescida da massa da própria base com os pistões) e $g$ a aceleração gravitacional.

Para a combustão dos três pistões com massa de queda livre de $20 \mathrm{~kg}$ temos os seguintes dados: $m=21,4 \mathrm{~kg}$, sendo $1,4 \mathrm{~kg}$ a massa da base com os pistões e $20 \mathrm{~kg}$ a massa acrescida sobre a base com os pistões, $g=9,8$ $\mathrm{m} / \mathrm{s}^{2}$ e $\Delta h=3,8 \mathrm{~cm}$, diferença de altura esta observada na Figura 5 De modo que pode-se afirmar que a energia mínima ${ }^{1}$ liberada na queima das três amostras de algodão sob a carga de $20 \mathrm{~kg}$ é de $U_{g}=8,0 \mathrm{~J}$. Dividindo este valor por três, uma vez que foram três amostras queimadas, obtemos a estimativa de energia liberada por amostra em $2,7 \mathrm{~J}$.

Já para a carga de $15 \mathrm{~kg}$ foi observado, nos cinco vídeos produzidos, que apenas dois dos três pistões geraram a combustão da amostra de algodão. Para este caso os

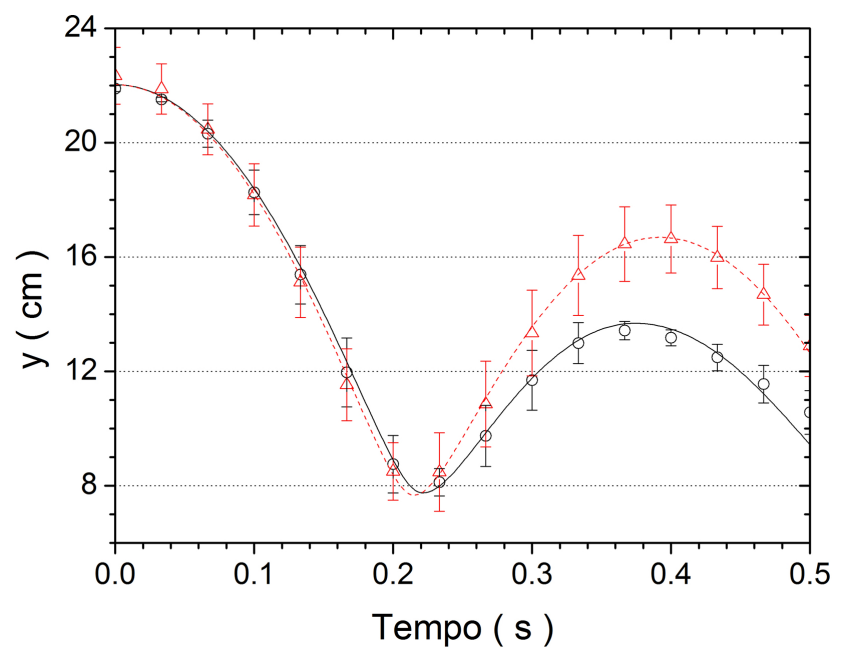

Figura 4: Trajetória média da base com os pistões sem queima do algodão (círculos pretos) e com queima de algodão (triângulos vermelhos) para carga de $15 \mathrm{~kg}$ sobre a base com os pistões. As linhas de fundo foram geradas numericamente de acordo com a equação de movimento (10), sendo a linha sólida preta associada aos parâmetros $f_{1}=9,6 \mathrm{~N}$ e $f_{2}=0,58$ e a tracejada vermelha associada aos parâmetros $f_{1}=2,9 \mathrm{~N}$ e $f_{2}=0,72$.

${ }^{1}$ Esse é um valor mínimo pois parte da energia liberada na queima já foi dissipada em atrito durante a subida da massa $m$ até o pico da trajetória. 
dados disponíveis são: massa de queda livre $m=16,4$ $\mathrm{kg}$, sendo $15 \mathrm{~kg}$ da massa sobre a base com pistões e 1,4 $\mathrm{kg}$ a massa da própria base com pistões, $g=9,8 \mathrm{~m} / \mathrm{s}^{2}$ e $\Delta h=3,2 \mathrm{~cm}$, diferença esta observada na Figura 4 Com isso, a estimativa de valor mínimo para a energia liberada na combustão é de $U_{g}=5,1 \mathrm{~J}$. Dividindo esta energia por dois, uma vez que foram duas as amostras queimadas, obtemos a energia liberada por amostra de $2,6 \mathrm{~J}$, que é consistente com o resultado de queima para três isqueiros pneumáticos.

Uma vez que a carga de $10 \mathrm{~kg}$ não gerou a combustão da amostra de algodão e a carga de $15 \mathrm{~kg}$ gerou tal combustão, pode-se afirmar que uma estimativa da força mínima necessária para acionar o isqueiro pneumático é de aproximadamente 5,5 kgf ou $54 \mathrm{~N}$, que corresponde aos 16, 4 kgf dividido por três, lembrando que a experiência de sala de aula comprime apenas um isqueiro pneumático [3].

Sabendo a energia por pistão liberada na queima e, a partir dos gráficos nas Figuras 4 e 5 sendo possível estimar o tempo necessário para fechamento de um ciclo de descida e subida, a potência por pistão pode ser calculada. A energia liberada por pistão é de $\Delta E=2,6 \mathrm{~J}$ enquanto que o tempo aproximado para o ciclo de descida e subida da base com os pistões é aproximadamente $\Delta t=0,38 \mathrm{~s}$. Com isso, a potência deste nosso equipamento é estimada em

$$
\text { Pot }=\frac{3 \Delta E}{\Delta t} \simeq 21 \mathrm{~W}
$$

ou, nas unidades usuais para motores automotivos, teríamos um "motor" com volume total de operação dos 3 pistões de $0.044 \mathrm{~L}$ (para comparar com carros 1.0L, 2.0L etc.) ou 44 cilindradas (para comparar com motos 125 cc, 250 cc etc.) gerando a potência total de $0,029 \mathrm{cv}$.

Para finalizar a análise quantitativa das trajetórias obtidas aplicamos a Segunda Lei de Newton sobre a base com os pistões. Consideramos as seguintes forças geradoras da dinâmica observada ${ }^{2}$, peso $(P)$, força do ar comprimido sobre os pistões $\left(F_{a r}\right)$ e força de atrito $\left(F_{a t}\right)$. A força de atrito e a força do ar comprimido, conforme veremos, conterão parâmetros livres que possibilitarão ajustar a curva teórica aos dados experimentais.

A força peso é quantificada por meio da expressão:

$$
P=-m g \text {. }
$$

A força do ar comprimido sobre cada pistão é dada pelo produto da pressão no interior de cada camisa $(p)$ pela área da base do pistão $\left(\pi r^{2}\right)$, ou seja

$$
F_{a r}=3 p \pi r^{2}
$$

onde o fator 3, nesta expressão, é resultado de somarmos a força do ar comprimido sobre cada um dos três pistões em atividade e que, por sua vez, estão conectados à base com pistões cuja dinâmica estamos tentando descrever.

\footnotetext{
${ }^{2}$ Estando todas as forças contidas na direção vertical não utilizaremos a notação vetorial, apenas adotaremos como sentido positivo a orientação para cima.
}

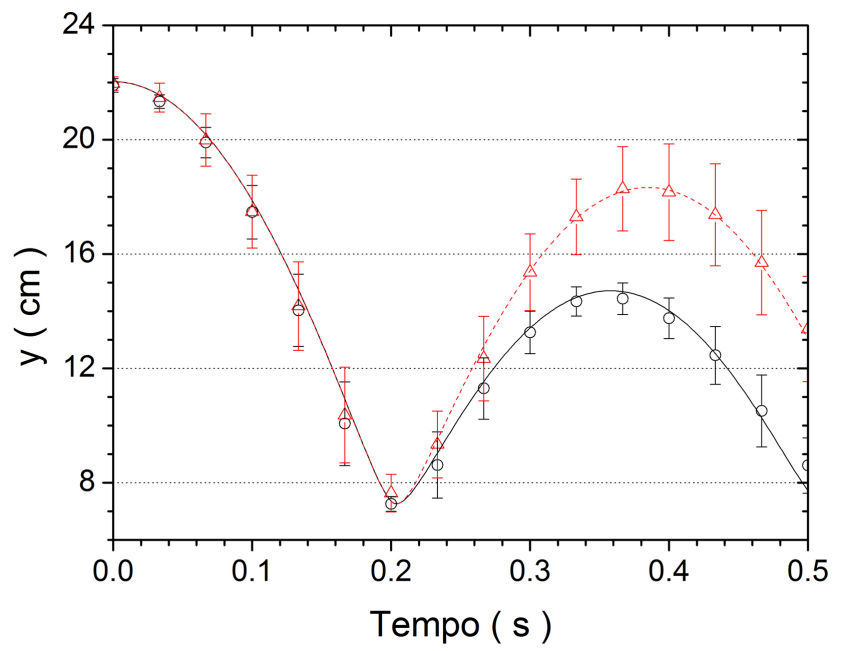

Figura 5: Trajetória média da base com os pistões sem queima do algodão (círculos pretos) e com queima de algodão (triângulos vermelhos) para carga de $20 \mathrm{~kg}$ sobre a base com os pistões. As linhas de fundo foram geradas numericamente de acordo com a equação de movimento (10), sendo a linha sólida preta associada aos parâmetros $f_{1}=0 \overrightarrow{\mathrm{N}}$ e $f_{2}=0,56$ e a tracejada vermelha associada aos parâmetros $f_{1}=0 \mathrm{~N}, f_{2}=0,78$.

Uma vez que utilizamos o modelo de compressão adiabática de gás ideal diatômico, a pressão $p$ em um instante qualquer do movimento é quantificada através da expressão

$$
p=p_{0}\left(\frac{h_{0}}{h}\right)^{\gamma}
$$

onde $\gamma=7 / 5$ para um gás diatômico, $p_{0}=0,96$ atm corresponde à pressão no interior da camisa antes do início do processo de compressão, $h_{0}=15,3 \mathrm{~cm}$ corresponde à altura do pistão no início da trajetória de compressão e $h$ é a altura do pistão em um instante qualquer do movimento do pistão.

Sendo notado que os pistões estão mecanicamente acoplados à base com pistões, de modo que o movimento destes implica movimento daquela e vice-versa, entendese que a posição $y$ da base com pistões obtida por meio da análise dos vídeos está associada à altura $h$ por meio de uma constante aditiva. Em outras palavras, o movimento dos pistões é escrito em função do movimento da base com os pistões por meio de uma expressão do tipo

$$
h=y-y_{k}
$$

sendo a constante $y_{k}=6,7 \mathrm{~cm}$ em nossa experiência.

Com estas informações, a força do ar comprimido sobre a base com os pistões é avaliada por meio da expressão

$$
F_{a r}=\frac{3 \pi}{4} p_{0} d^{2}\left(\frac{h_{0}}{y-y_{k}}\right)^{\gamma}
$$

onde foi trocado, nessa expressão final, o raio $r$ pelo diâmetro $d=2 r=1,10 \mathrm{~cm}$ dos pistões.

O modelo de força de atrito adotado foi o de força constante e de sentido oposto ao da velocidade dos pistões, 
sendo escrita em termos de um parâmetro livre, $f_{1}$, sob a seguinte forma

$$
F_{a t}=-f_{1} \operatorname{sgn}\left(\frac{d y}{d t}\right)
$$

em que $\operatorname{sgn}(x)$ é uma função que extrai o sinal de $x$, ou $\operatorname{seja}, \operatorname{sgn}(x)=1$ se $x>0$ e $\operatorname{sgn}(x)=-1$ se $x<0$.

A equação de movimento para a base com pistões toma, então, a seguinte forma

$$
m \frac{d^{2} y}{d t^{2}}=-m g+\frac{3 \pi}{4} p_{0} d^{2}\left(\frac{h_{0}}{y-y_{k}}\right)^{\gamma}-f_{1} \operatorname{sgn}\left(\frac{d y}{d t}\right)
$$

tendo apenas o parâmetro $f_{1}$, correspondente ao módulo da força de atrito, como parâmetro livre. Uma comparação entre as dinâmicas experimental e aquela oriunda dessa equação de movimento revelou a necessidade de melhorar o modelo de força resultante para poder melhor ajustar as dinâmicas prevista (modelo) e observada (dados experimentais).

Uma reflexão a respeito da dinâmica de queda da base com pistões e do processo de compressão do gás levou a levantar a hipótese de escape de partículas da câmara de compressão para o ambiente no instante de máxima compressão do ar. Caso houvesse esse vazamento, o reflexo direto e observável na subsequente dinâmica posterior ao vazamento seria uma redução da força $F_{a r}$.

Notando que $F_{a r}$ tem proporção direta com a pressão no interior das câmaras de ar comprimido e que essa pressão é diretamente proporcional ao número de partículas aprisionadas naquelas câmaras (gás ideal), um escape de partículas poderia ser levado em consideração no modelo de força resultante por meio da introdução de um segundo parâmetro livre que reduziria o módulo da força $F_{a r}$ em cada instante de máxima compressão do ar. Este segundo parâmetro, denominado $f_{2}$, seria adimensional e teria módulo entre 0 e 1 , sendo que $f_{2}=0$ representaria um escape total de partículas no instante de máxima compressão e $f_{2}=1$ um escape nulo de partículas naquele instante.

Por fim, consideramos ainda que em cada instante de máxima compressão haveria o mesmo escape de partículas. Isso significa que é necessário, durante a simulação do modelo teórico, contabilizar o número de vezes que a máxima compressão foi atingida. Indicando esse contador por $n$ estabelece-se a seguinte situação: desde o instante inicial da dinâmica até a primeira ocorrência de máxima compressão têm-se $n=0$, a força do ar não sofre redução alguma por ainda não ter havido vazamento algum; entre a primeira e a segunda ocorrência de máxima compressão o contador teria o valor $n=1$ e a força do ar teria seu valor total reduzido por um fator $f_{2}$, pois ocorreu um primeiro escape de partículas; entre a segunda e a terceira ocorrência de máxima compressão a força do ar seria reduzida pelo mesmo fator $f_{2}$ duas vezes, ou seja, o contador teria valor $n=2$ e a força do ar seria multiplicada por $f_{2}^{2}$; e assim por diante, até o instante em que a base com pistões cessa seu movimento.
Com isso, a equação de movimento para a base com os pistões foi reescrita como

$$
m \frac{d^{2} y}{d t^{2}}=-m g+f_{2}^{n} \frac{3 \pi}{4} p_{0} d^{2}\left(\frac{h_{0}}{y-y_{k}}\right)^{\gamma}-f_{1} \operatorname{sgn}\left(\frac{d y}{d t}\right)
$$

em que é possível verificar a presença do segundo parâmetro livre, $f_{2}$, no termo que corresponde à força total do ar comprimido sobre a base com os pistões (o segundo termo ao lado direito da igualdade na equação (10) juntamente com seu expoente contabilizador de vezes em que a máxima compressão é atingida durante a evolução da base com os pistões, o expoente $n$ em $f_{2}$. Esta equação foi resolvida numericamente utilizando o método de Runge-Kutta de quarta ordem [7] e ofereceu bom acordo com os dados experimentais, conforme pode ser notado no ajuste obtido entre a linha teórica e os pontos experimentais apresentados nas figuras 3,4 e 5 .

A escolha dos melhores parâmetros $f_{1}$ (atrito) e $f_{2}$ (escape de partículas na máxima compressão) foi feita da seguinte forma: o espaço de parâmetros foi dividido em uma grade de $100 \times 100$ pontos, sendo $f_{1}$ varrido no intervalo de valores $[0, m g / 2]$, com $m g$ o peso correspondente à massa em movimento, e $f_{2}$ varrido no intervalo de valores $[0,1]$. Para cada par de parâmetros da grade realizava-se uma simulação da equação de movimento 10 e, então, a soma dos quadrados das distâncias entre o resultado dessa simulação e os correspondentes dados experimentais (somente os primeiros 15 pontos experimentais de cada uma das 5 trajetórias distintas aqui relatadas) era armazenada. O par de parâmetros que forneceu o menor valor para a soma dos quadrados das distâncias foi aquele escolhido para traçar as linhas de fundo em cada uma das Figuras 3,4 e 5

\section{Resultados e discussões}

Após o vislumbre de um relativo esforço para descrição da construção e uso do isqueiro pneumático para aquisição reprodutível de dados associados ao seu funcionamento cabe relembrar o comentário do primeiro parágrafo da Seção 2 "Para construir um isqueiro pneumático a ser utilizado em sala de aula bastam uma base de madeira, um pequeno cilindro de aço a ser fixado na base, um tubo de acrílico e o pistão de aço com um cabo em sua extremidade." De modo que a metodologia e os dados aqui apresentados visam dar uma noção quantitativa das grandezas envolvidas no funcionamento do isqueiro pneumático e servir de auxílio para qualquer professor poder explicar com razoável segurança aos seus alunos mais interessados como proceder para estimar os valores de temperatura, pressão e energia liberada no processo de queima da amostra de algodão.

A abordagem foco deste estudo se deteve apenas na Física envolvida no processo. No entanto, Física e Química podem conversar neste experimento por meio do

\footnotetext{
${ }^{3} \mathrm{Ou}$ seja, a escolha de parâmetros foi feita pelo método dos mínimos quadrados.
} 
vislumbre irrefutável da conversão de energia química de ligações moleculares em energia térmica que, por fim, manifesta-se como energia mecânica (potencial gravitacional).

Os gráficos das Figuras 4 e 5 , juntamente com o experimento do isqueiro pneumático, podem auxiliar uma explicação simples para o funcionamento dos motores automotivos atuais onde, mais uma vez, a química envolvida no processo de queima de cada combustível, com liberação de energia característica para cada reagente, pode ser explorada.

Experimentos semelhantes poderiam ser utilizados para quantificar a energia liberada na queima de papel ou amostras de palha, evidenciando esta diferença de energia por material combustível.

Por que não aproveitar para explicar que o diesel queima expontaneamente nos motores, assim como o algodão do experimento, enquanto que o álcool e a gasolina precisam de uma ignição elétrica no instante de maior compressão? E o que impede de explorar o fato visível de que as reações químicas, ao fornecerem energia no interior de nosso corpo, dão suporte à vida e, com isso transitar para a Biologia?

A riqueza de possibilidades de exploração dos resultados obtidos para movimentar o assunto entre distintas formas de conhecimento torna esse equipamento simples muito útil para o ensino.

Já na parte final da Seção 4 notamos a presença de conceitos da mecânica, ainda dentro da Física, para descrever a trajetória da base com os pistões. Seja notado que esta parte da análise de dados pode ser usada para exemplificar o processo de modelagem na descrição quantitativa de um fenômeno. Embora não tenhamos nos detido para explicar as razões pelas quais os 2 parâmetros utilizados tiveram os seus valores conforme apresentados, cabe explicitar a importância que uma metodologia objetiva têm para a avaliação destes parâmetros, dando-se destaque ao bom ajuste obtido entre os dados coletados experimentalmente e as linhas advindas da resolução da equação de movimento. Esta conversa entre dados experimentais e resultados de modelagem teórica serve, no contexto de ensino, para evidenciar que, pelo menos nas Ciências Exatas e da Terra, os dados experimentais fornecem o veredito final em um processo de validação (ou não) de um modelo teórico que se propõe a descrever um dado fenômeno. Essa comparação tem sido o filtro pelo qual qualquer proposta de compreensão quantitativa do mundo precisa passar desde o Renascimento.

Espera-se que o relato aqui apresentado seja útil para estímulo do uso de experiências em sala de aula, seja para o ensino de Termodinâmica, Física ou Química, seja para gerar conversas entre diferentes áreas do conhecimento e suas conexões e interdependência inextricáveis. Também, espera-se que, especificamente, o equipamento isqueiro pneumático se torne um pouco mais conhecido, dada sua simplicidade e potencialidade de uso.

\section{Referências}

[1] R. Fox, Technology e Culture 10, 355 (1969)

[2] G. Falk, European Journal of Physics 6, 108 (1985).

[3] J. Güémez, C. Fiolhais e M. Fiolhais, European Journal of Physics 28, 1199 (2007).

[4] <https://physlets.org/tracker/>, acessado em $21 / 09 / 2018$.

[5] P.A. Tipler e G. Mosca. Física para cientistas e engenheiros (LTC, São Paulo, 2009), $6^{\mathrm{a}}$ ed., v. 1.

[6] D. Halliday, R. Resnick e J. Walker. Fundamentos de Física (LTC, São Paulo, 2009), $8^{\text {a }}$ ed., v. 2.

[7] P.L. DeVries. A first course in Computational Physics (John Wiley and Sons, New York, 1994). 